\title{
The electronic petition as a way to influence the power available to every citizen: The role and prospects in Ukraine
}

\author{
Dmytro Luchenko \\ Yaroslav Mudryi National Law University, Kharkiv, Ukraine
}

\begin{abstract}
The article substantiates the thesis that electronic petitions are potentially capable of acting as an effective means of challenging illegal decisions, actions, and inactivity of state authorities. In this case, the institution of the electronic petition is a mechanism that creates comfortable conditions for expressing the will of citizens, regardless of their place of residence. The article analyzes the status of the legal regulation of the institute of the electronic petition in Ukraine and the practice of its functioning. The shortcomings of the legislation on electronic petitions that negatively influence the effectiveness of this institute are systematized. The study proposes a number of measures to improve the effectiveness of electronic petitions, namely: the implementation of educational activities among the population (especially rural areas) regarding the appointment and use of the institution of electronic petition; establishing of an imperative status for petitions that overcome the minimum of votes in their support; preventing the loss of votes by the same type of petition with identical appeals; blocking irrelevant petitions; improving the interface of relevant electronic resources on which petitions are published.
\end{abstract}

Key words: electronic petition, effectiveness, progressive institution, legislative regulation.

\section{Introduction}

Development of ICT (Information and Communication Technologies) has created the preconditions for providing a comfortable way of expressing the will of citizens, regardless of their place of residence. People living in villages have the same opportunities to directly influence the authorities as the residents of the capital through such an important institution of e-democracy as the electronic petition. Its value and potential in ensuring access of citizens to the management of state affairs is difficult to overestimate. All the necessary for this is access to the Internet, authorization and the desire to participate in solving the urgent problems of the state. Moreover, the institute of electronic petitions provides an opportunity to influence the authorities at any moment, and not only during the elections. These factors actualize the need for further research in the issue of the institute of electronic petitions in order to increase its effectiveness.

Despite the fact that E-petition is an extremely progressive institution in modern democracies, the practice of their functioning in Ukraine is not effective. On the one hand, Ukraine ranks 32nd in the Top 50 performers in e-participation in 2016, according to the United Nations E-Government Survey 2016 [1], but many researchers point to the threats and weaknesses functioning e-petitions in Ukraine. Volodymyr Reshota, for example, points 
out that the current regulation of electronic petitions can become a tool for manipulating and popularizing populist ideas that have nothing to do with the rule of law [2]. Anastasia Kostyantynivska also notes that in order to become truly effective, E-petitions should be regulated more transparently and openly, and citizens should exercise effective control over the petition process [3].

Thus, the aim of the study is to identify the weaknesses of the institute of E-petitions in Ukraine as well as to find ways of improving the legislative regulation of E-democracy in Ukraine. The specific task of the article is to search for specific proposals to improve the legislative and functional regulation of the filing and petition process. The aim of the proposed innovations should be to simplify the access of the population to petitions, as well as to impose additional obligations on officials on the consideration and response to petitions.

Accordingly, for the purposes of the article, quantitative and qualitative methods of scientific research will be used. A quantitative method will allow us to determine the statistical indicators of the use of E-petitions in Ukraine and, most importantly, to find out the effectiveness of this institution and its impact on meeting the needs of civil society. The qualitative method will allow finding solutions to the shortcomings of legislative regulation of E-petitions in Ukraine and, accordingly, improve this institution.

\section{Problems and prospects of electronic petitions in Ukraine}

In Ukraine, the procedure for filing and reviewing electronic petitions has been regulated at the legislative level by only one article (23-1) of the Law of Ukraine "On Citizens' Appeal" [4]. Part 1 of this article stipulates that citizens may apply to the President of Ukraine, the Verkhovna Rada of Ukraine, the Cabinet of Ministers of Ukraine, the local self-government body with electronic petitions through the official website of the body to which it is addressed or the website of the public association that carries out collection of signatures in support of electronic petition. The specified norm predetermines the peculiarity of the electronic petition as a form of citizens' appeal, which is submitted exclusively to the subjects of public authority, since the rest of the appeals provided by the Law may also be submitted, for example, to enterprises, institutions, and organizations irrespective of the forms of ownership.

Electronic petition as an element of E-democracy promotes: (1) strengthening participation, initiative and citizen engagement at the national, regional and local levels of public life; (2) improving transparency of the democratic decision-making process and accountability of democratic institutions; (3) improving the sensitivity/reciprocal reaction of authorities to citizens' appeals; (4) promotes public debate and attention of citizens to the decision-making process. Therefore, it can be stated that electronic petitions as one of the elements of e-democracy are means to improve access of citizens to the authorities and their communication with officials and elected politicians.

It should also be noted that the institute of electronic petitions has such quality as prevention of sharp social tensions that may transform into armed conflicts. The experience of Ukraine shows that if the authorities listened to the voice of the people (especially those who live on the periphery, in small towns and villages), and people had an effective mechanism to convey their own will to the authorities, there would be no Maidans, and no revolutions, during which people from all over the country came to Kyiv to express their dissatisfaction with the state policy.

Even Francis Fukuyama in his famous book, The End of History and the Last Man, pointed out that the model of a state with a liberal and democratic system is the most perfect form of social organization. The scientist explained this by the fact that only liberal democracies set maximum opportunities for controlling the state authorities by population. In liberal democracies, people can convey their views to state power and thus they feel 
their significance role and recognition. Totalitarian countries do not have such mechanisms that would ensure the recognition of ordinary citizens, so they all sooner or later fall [5]. Electronic petitions can be an effective mechanism to ensure that people's desires are brought to government.

Whereas, electronic petitions, on the one hand, allow the authorities to quickly receive information on issues that are socially acute and resolve them without transformation into critical tensions, and on the other hand, provide citizens with a comfortable, economical but effective way of expressing their own will. Electronic petitions allow citizens to feel that they are the source of power, to realize how they are involved in the formation of the state policy and the responsibility for it. However, this is possible only under two conditions: (1) the authorities want to listen to the voice of their citizens; (2) the state has established at the legislative level an effective and transparent mechanism for the implementation of electronic petitions and for its own responsibility.

The detailed analysis of legal acts that establish the procedure for the implementation of the citizens' right to electronic petition in Ukraine, as well as the whole array of electronic petitions and their responses, which were made public on the official sites of the President of Ukraine, the Verkhovna Rada of Ukraine and the Cabinet of Ministers of Ukraine during their operation, indicate the fact that the institute of electronic petitions in Ukraine, although implemented in July 2015, does not fulfil the task assigned.

A number of shortcomings in the legislative regulation of the institute of electronic petitions turned it into fiction, distorting the very idea of this element of E-democracy. Today, electronic petition in Ukraine is simply the usual appeal of the citizen to the subject of power, which has become public, but does not cause any obligations on the part of the addressee, except for the duty to respond promptly (we emphasize - to provide an answer, not to decide asked question).

Let us consider the weaknesses in the legislative regulation of the institute of electronic petitions in Ukraine. First of all, it should be noted that the legislation does not distinguish between electronic petitions, which are complaints, does not set any particulars for them in relation to registration and consideration. This makes it impossible to emphasize the authorities' attention to socially acute problems. Such level of regulation is insufficient for the creation of an effective tool for e-democracy. Moreover, the indication in Part 17 of Art. 231 of the Law of Ukraine "On Citizens' Appeal" about the possibility of elaboration by the subjects of consideration of electronic petitions their own procedural acts, which will regulate the procedure of work with petitions, creates the risks of possible abuses.

The object of our statistical analysis is the official website of the President of Ukraine. This resource not only works with electronic petitions longer than others but also is the most popular among citizens, including complaints of decisions, actions or inactivity of public authorities. August 29, 2018, was three years since the first electronic petition was made public on the official site of the President of Ukraine. As of August 29, 2018, citizens of Ukraine registered 30,467 petitions on through this Internet resource. The biggest share $(16,716)$ was registered in the first four months (an average of 4179 petitions per month), indicating an extraordinary public interest in this progressive achievement of world democracy.

Subsequently, the activity of citizens in the use of electronic petitions has declined significantly. For example, in 2016, only 7759 petitions were registered (that is, an average of 646.5 petitions per month). And in the first eight months of 2018, 2852 petitions were registered (an average of 356.5 petitions per month). Thus, in 2018, the number of citizens who used the procedure for addressing the President of Ukraine through the electronic petition has decreased by almost 12 times compared to 2015 . We cannot say that such a decrease was the result of the reduction of socially acute issues, which are traditionally 
the subjects of petitions. Unfortunately, the tendency of reduction of this form of appeal to public authorities is determined by the low level of effectiveness of the electronic petition's mechanism in Ukraine.

The analysis of the data, contained on the site of the President of Ukraine, gives the following figures, which reflect the real level of effectiveness of electronic petitions. Thus, as of the beginning of 2019, with over 30 thousand petitions filed with the President of Ukraine, only 46 petitions gathered 25 thousand votes in their support for a fixed term. 43 of them received a response from the President. Thus, the low percentage of petitions that overcame the 25,000 barriers (only 1 petition from nearly 700) has led to a decrease in the interest of Ukrainian citizens in the electronic petition as a way of solving socially acute issues.

In addition, a meaningful analysis of the responses to the petition to the President of Ukraine indicates that the vast majority of the applicants received formal answers of power and not real answers. Thus, among the 43 petitions that received the response of the President of Ukraine:

- in 3 cases it was refused to satisfy the petition;

- 4 electronic petitions are satisfied;

- 32 were redirected to other entities (the Cabinet of Ministers of Ukraine, the Constitutional Commission, etc.), but neither deadlines nor the obligation to report on the results of the consideration were mentioned;

- the answer to 4 petitions does not fully answers the question.

Thus, on average, only 1 electronic petition for 10 thousand registered on the site of the president of Ukraine reaches its result. The majority of petitions considered by the President are not rejected, but redirected for consideration by other subjects of power. We believe that such an answer is inappropriate. It is worthwhile to determine at the legislative level that one of the following responses to an electronic petition may be considered appropriate:

1. When the petition is substantially satisfied and the appropriate measures are taken, in particular, the complaint is considered or directed to the bodies that play the role of the institutes of the indirect appeal. In the case of the abolition of a decision of a particular collegial body, including the Parliament, it should be about the obligation of this body to urgently consider abolishing the relevant decision or taking measures to eliminate its consequences (for example, if it means the abolition of an act already executed).

2. When the petition is not satisfied, it is exhaustively explained why it is not satisfied. The clarification should be such as to maximize the conviction of the applicant and those who supported the petition that their satisfaction is impossible or inappropriate in the specific circumstances.

3. When, on the basis of the results of the consideration of the petition, an order is drawn up to another entity competent to resolve the issue, but information on the timing and results of its execution, the measures taken and the results obtained are posted on the site. This should provide the opportunity for anyone interested in this petition and the outcome of its consideration, to obtain comprehensive information directly in response to a petition. The answer cannot be exhausted by information that the question is redirected to someone, charged with understanding, studying opportunities, etc., which gives the impression of the incompleteness of the case.

In any case, the state authority considering the electronic petition should try to solve it as much as possible, as well as substantiate its response in order to exclude any ambiguity.

To be objective, it should be noted that the low level of support for electronic petitions is due to two other factors. The first is that not all citizens of the country, especially those living in rural areas, have the technical capacity to register their own or to support an already 
registered electronic petition. A significant number of people (mostly older) do not have any devices. According to Newzoo, in May 2017 only 23.5\% of Ukrainians have modern smartphones. The rest have either a mobile phone or nothing at all [6]. In addition, the vast majority of Ukrainian citizens are not aware of the institute of electronic petitions, do not understand its significance, and do not have the skills to use it. So, the author of this article in 2017 visited the leading law schools and faculties in the country with lectures devoted to the problems of the electronic petitions. A survey conducted during this event showed that about half of the audience (including law students, practicing lawyers and teachers) were not familiar with this institution and did not understand its meaning. Of course, this indicator is much lower among ordinary citizens, and this is a deterrent to the disclosure of the capacity of the institute of electronic petitions.

The second factor in the low level of support for electronic petitions is due to the quality of the most registered petitions. This concerns both the nature of resolved issues, which often do not cause any interest from the overwhelming majority of citizens, as well as the quality of their text. Among the disadvantages of describing the most frequently encountered e-petition text, one should separately highlight the following as the most significant: inconsistency; incomprehensibility of the wording; lack of clear proposals or requirements; the presence of numerous grammatical errors.

We emphasize that the irresponsible attitude of citizens towards the formulation of an electronic petition, the submission of it without a need, for the sake of entertainment or own PR, severely damages this kind of appeal to public authorities. On the one hand, such a frivolous approach discredits both the applicants themselves and their legal institution, and on the other, no matter how senseless and pointless electronic petition, its representation is guaranteed to launch a certain mechanism that requires the use of state resources (means and time). In this regard, it would be advisable to establish the duty of citizens to refrain from abusing their right to electronic petition, and possibly to provide for the right of the state to recover from the court costs related to the administration of a pointless petition. However, it is necessary to do so in such a way that in no way does it restrict the right of citizens to submit substantiated electronic petitions (especially those containing a complaint against a decision, action or inaction of public authorities).

The next reason that affects the effectiveness of electronic petition as an appeal to the authorities and, accordingly, its popularity, is the non-binding nature of the petition gaining the required number of votes in support. The legislation established that an electronic petition, which received support for more than 25 thousand people in three months, is considered in a special procedure. However, if the petition does not receive the above support, it will also be considered, but in the manner prescribed by law for ordinary citizens' appeals (Part 10 of Article 231 of the Law of Ukraine "On Citizens' Appeal"). The question arises: what is the meaning of an electronic petition if it does not give the applicant and the citizens who have supported it any advantage in the form of an effective mechanism of influence on power? After all, the obligation of the addressee of the electronic petition to consider it according to special order is not the obligation to make every possible effort to solve the problem. It is obvious that under the current order, the procedure for reviewing the electronic petition does not provide any advantages, except for the possibility to address the President of Ukraine and other authorities in a public way.

This problem is critically important for the further functioning of the electronic petition mechanism. The international community considers this way of appeal as the most progressive. The mechanism of the electronic petition is capable of ensuring the direct impact of citizens on the authorities. Also, electronic petition is an instrument for the effective implementation of the rule of law, which, along with other institutions of a democratic society, makes it possible not only to appeal to higher authorities or local self-government bodies, but 
also to attract other people's attention to a certain problem, get their support and force the authorities to act. As a result, state authorities will act without being guided by their own discretion, but in the direction desired by society.

There is no doubt that the level of effectiveness of the institute of electronic petitions is an indicator of the maturity of democracy in the country. Ukraine still has much to work on improving the regulation of electronic petitions, since it is clear that the existing mechanism needs to be rethought and reformatted. The leverages of power should be created. Such leverages will force the authorities to pay attention to problems that really concern society, including in those situations where citizens seek to cancel an unlawful normative or individual legal act. As an option, electronic petitions should become imperative if they overcome the minimum level of signatures, that is, they should become a draft law, as it is envisaged in a number of countries. Such a procedure exists, for example, in Finland, where petitions, which have collected 50 thousand signatures, automatically become a draft law and the parliament is obliged to consider them as a priority. In addition, the regulations of the Latvian legislature stipulate that any petition, which has received support from 10,000 citizens, must necessarily be included in the agenda of the parliament. These are vivid examples that demonstrate the state's readiness to take into account the opinions of its citizens. Such a mechanism ensures equal opportunities for the inhabitants of small towns and villages to take an active part in public administration, to draw the attention of the authorities to the urgent problems of the regions and to demand the resolution of such crisis situations.

We disagree with the norm of Ukrainian legislation (Part 10 of Article 23-1 of the Law of Ukraine "About Citizens' Appeal"), which provides that a petition that has not gained 25 thousand votes is considered as a simple appeal by citizens. This is a misleading practice since a petition that has received at least one voice in support of it is already an appeal of several individuals. We are convinced that the response to such an electronic petition should be directed not only to the applicant but also to the person who gave his vote in support of the petition. Another option is to publish petition responses through the site where the petition was posted. Such a requirement should be fixed at the level of the law.

Moreover, a complaint about a decision, action or inaction of a public authority submitted through an electronic petition must obviously be considered in a separate procedure, unlike other types of appeals. This means that in this case the petition does not concern the proposal to improve the legal regulation, for example, certain social relations, but the need to restore the violated rights, to protect the person (a group of persons) from illegal misconduct. Therefore, the timing of consideration of such complaints should be reduced, and the results of the review should be subject to appeal in court.

The next reason for the low efficiency of electronic petitions in Ukraine is the lack of a mechanism for protecting against the loss of votes. The current procedure allows registering a petition even if a similar petition has already been registered before. On the other hand, voices for similar petitions are not united. For example, the requirement to reduce customs duties when importing into Ukraine used cars within three months (from June to August 2017) was put forward in the 17 registered on the site of the President of Ukraine electronic petitions. Another 7 petitions for the specified period have similar content. In addition, on the site of the Cabinet of Ministers of Ukraine, there were also 2 petitions registered with similar appeals at the specified time. That is, 26 electronic petitions on one issue simultaneously gathered votes for their support. As a result, none of the 26 petitions received the required number of votes, although the very number of them (petitions) should signal the authorities of the high degree of social acuteness of the issue. The result of the inaction of the authorities in resolving this issue was the numerous rallies and blockages of roads that took place in Ukraine in 2018 . 
The unfriendly interface of sites where the electronic petition is made public is also evidence of the fact that the state has no intention of providing the effectiveness of the institute of electronic petitions. In Ukraine, these sites not only do not allow the convenient handling of petitions, promoting them through social networks, but also provide extremely limited tools for analyzing and systematizing already registered petitions.

In our opinion, recommendations for improving the toolkits of sites where electronic petitions are made public may look like this:

1. A website with petitions should block the possibility of losing votes if such statements are identical and identical. There should be a ban on registration of a petition, similar to the one already registered, where the collection of signatures began. The person registering his own electronic petition, similar to the content of a petition that is already registered and gaining votes, the service must offer to support a petition already registered or to register its own, but after the expiration of the time remaining for collecting votes for an already registered petition.

2. Currently, it is possible to sort petitions by the topics (for example, agrarian policy, land relations, transport, communications, education, etc.), by chronology, by the number of votes. Also, everyone can elect petitions with responses from authorities, petitions currently under consideration and petitions that are in the process of collecting votes. In our opinion, the following should be additionally provided:

a) search of electronic petitions by the date of registration;

b) search of electronic petitions for the keywords not only in the title but also in the text of the petition;

d) grouping of petitions according to the type of appeal (complaint, statement, proposal);

e) message users using mobile communication (SMS) or e-mail about the registration of a petition that is similar to the one that they previously supported or registered.

3. The site should have information (hints) on what issues related to the mandate of the body to which the electronic petition is addressed, as well as how to correctly write a petition (the wording of the informative and clear title, the writing of the content and the definition of the nature of the appeal (suggestions or requests)).

The electronic service should block the ability to register the following petitions:

- petitions that go beyond the mandate of the authority to which the petition is sent (in this case, the user should be offered to go to the official website of the authority authorized to solve the issues raised in the electronic petition and provide a corresponding reference to the law and the corresponding electronic resource);

- petitions that do not contain any requests, proposals or complaints;

- petitions concerning the introduction, cancellation, and reduction of taxes and other mandatory payments, the number of social benefits and wages.

\section{Conclusions}

Thus, we are proposing to introduce a number of innovations aimed at improving the legislative regulation and functioning of the electronic petition institute, which is designed to provide easy and comfortable access for citizens to the management of public affairs, regardless of their place of residence. In addition, our proposals will enable the authorities to promptly receive information on the urgent problems of the regions. 
We propose the introduction of various mechanisms aimed at increasing the impact of electronic petitions on state authorities, which will be implemented through granting petitions the status of imperative. Also, it seems necessary to implement a number of measures aimed at improving the tools of the sites on which electronic petitions are published.

Taking into account the above-mentioned, proposals will enable the creation of a truly effective electronic petition as an element of e-democracy, which is intended to initiate citizens (especially those living outside the capital) to participate in the formation of state policy, to ensure, in a civilized way, that they effectively and effectively bring to the consciousness of the government their actual expression of will and defend their rights.

\section{References}

[1] “Top 50 Performers in E-participation in 2016." United Nations E-Government Survey 2016 United Nations E-Government Survey, 2017, 197-217. doi: 10.18356/8e967554en

[2] Reshota, V. "Electronic Petition as a New Tool for Appeal to Public Administration Bodies.” Scientific Bulletin of the International Humanitarian University, 2015, 91-94. Available: http://www.vestnik-pravo.mgu.od.ua/archive/juspradenc15/ part_1/26.pdf

[3] Konstantynivska, A.K. "Electronic Petition as an Effective Tool for Political Participation of Citizens." Epistemological Studies in Philosophy, Social and Political Sciences 1(1-2), 88-95 (2017). doi: 10.15421/341809

[4] About Citizens' Appeal: Law of Ukraine dated 02.10.1996 No. 393/96-VR. Information from the Verkhovna Rada of Ukraine. 1996. No. 47. Art. 256 (with the following changes and replies)

[5] Fukuyama, F. The End of History and the Last Man. London: Penguin, 2012

[6] Hrytsyna, Mykhaylo. Poll: Top 50 Countries That Use Smartphones Most. Ukraine Is at Its Lowest Point in Europe. May 2017, Available: pingvin.pro/gadgets/newsgadgets/opytuvannya-top-50-krayin-yaki-najbilshe-korystuyutsyasmartfonamy-ukrayina-na-najnyzhchomu-mistsi-v-yevropi.html 